\title{
Twisted Ways from Melancholy to Depression (in Polish Lands)
}

\author{
Author: Mira Marcinów \\ Title: Historia polskiego szaleństw: Stońce wśród \\ czarnego nieba. Studium melancholii. \\ [The History of Polish Madness: Sun amidst the \\ Black Sky. Study of Melancholy] \\ Publishing house: Fundacja Terytoria Książki \\ Gdańsk 2017 \\ 459 pages + album

\section{Jakub Zawila-Niedźwiecki} \\ Center for Bioethics and Biolaw, Institute of Philosophy \\ University of Warsaw, Poland \\ j.zawila-niedzwiecki@uw.edu.pl \\ Received 21 October 2019; accepted 4 November 2019; \\ published 15 December 2019
}

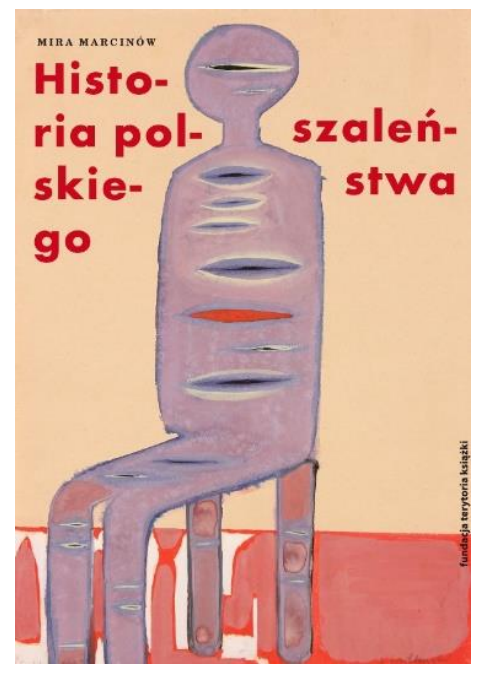

\begin{abstract}
This paper is a review of Mira Marcinów's book on history of melancholy in Poland. It is written from a perspective of bioethicist and philosopher of medicine interested in psychiatry and endeavours both presentation of the project for an English speaking reader and critical evaluation of this exceptional book with focus on value for different potential readers.
\end{abstract}

Keywords: Mira Marcinów; melancholy; depression; history of psychiatry; Poland.

Mira Marcinów's book poses a challenging task for the reviewer. Not because it's a difficult read-I will comment on this later on-but because it's hard to pinpoint what the book is actually about and to whom it's addressed. However, as Marcinów has admitted herself during author's meetings, this feature of the book is, to a certain extent, deliberate. The book, at the same time, is and is not: an academic monograph, anthology of texts and 
an album. It is, and it isn't a book about the history of ideas, philosophy of psychiatry, history of psychiatry and psychology, literary scholarship, philosophical anthropology and, last but not least, simply psychopathology. All these elements are combined into an integral whole and would be rather impossible to separate. On the other hand, though, the text is composed in a way that permits the reader to open the book on a random page and start reading, or-according to one of the comments expressed during a meeting with the author: "you can read the book without feeling that you have read it."

Undoubtedly, it is an academic work with all the expected elements, such as a long list of literature references (over 30 pages), but at the same time, it is a popular humanities book, written in a language that is supposed to be understandable for non-experts in the field, and finally - considering the album comprising prints, photographs, drawings and paintings related to melancholy that takes $1 / 8$ of the volume - it is also a form of artistic activity.

In the academic aspect of the book, the author makes use of her expertise in philosophy, contemporary psychology and clinical psychiatry-including her own clinical experience - and on top of that, of the toolbox of a historian, including history of terms and ideas, literary scholarship and knowledge of literature in general, combining all of them into a synergistic whole. As a result, we get a text whose target reader remains unknown. Indeed, Dr Marcinów has put a lot of effort into using transparent language, avoiding academic jargon, but in order to fully appreciate the information included in the book, one would need broad — and quite niche — knowledge, available only to very few historians of psychiatric thought, philosophers of psychiatry and philosophising clinicians. Otherwise, some of the references will remain unclear and elusive. If it were necessary to indicate a group of people that definitely should read this work, it would be clinicians interested in philosophy and theory, as they will find here a rich source of materials that can serve as a point of departure for some creative input into contemporary clinical theory and practice (more on this topic later on).

The book comprises three parts: 1 . The author's own original study on the topic of melancholy in Polish psychiatry in the $19^{\text {th }}$ century and before, together with its cultural background; 2. A selection of reference texts that served as material for the first part, followed by the usual list of references and a table of contents; 3 . The above-mentioned album.

The first part - "the study," is further subdivided into two sections: section I, a theoretical and methodological section that describes the research methods applied, research questions, materials, reference literature on the global history of psychopathology of melancholy ("melanchology," as the author calls it), and section II organised in line with the classical medical division into diagnosis, aetiology and treatment.

First, the author describes the sources, the history of concept development (together with a glossary of terms) related to a shift in the perception of melancholy among Polish psychopathologists, and later she presents a long list of clinical cases based on reference materials, organised according to different methods used to reach a diagnosis, conditions leading to 
the illness, and therapeutic methods. This part concludes with an attempt to describe the specificity of Polish melancholy, as opposed to the global variant.

The second part - the anthology — contains a selection of texts by $19^{\text {th }}$-century psychopathologists, grouped around similar problems: e.g. forensic psychiatry, children's or women's psychiatry, etc. Although this part ends with a list of sources from which the texts have been taken, the critical apparatus provided to us herein is very scarce; the anthology seems to play a rather illustrative — and not historical and critical—role, especially considering that some texts are only quoted in fragments.

The album, printed on a different kind of paper, presents images of $19^{\text {th }}$-century psychiatry - this time all around the world - that can shock an unaccustomed reader. There are images depicting patients, therapeutic methods, as well as representations of melancholy in paintings and in culture.

The type of narrative is somewhere in between a contemporary scientific article-with the specific form of citations, unusual for Polish humanities and typical of a medical publication, being a factor here-and a popular humanities book. In spite of this tangible tension, it is by no means a drawback, yet a reader used to essays will be surprised on encountering the first table. Although the author explains cultural processes and the development of anthropological thought in philosophy, she also tries to analyse, even quantitatively, some features of 19th-century psychopathologies. For example, we may find here tables of symptomatology of melancholy, together with the incidence of given groups of symptoms.

The title of Mira Marcinów's book is an obvious reference to a work by Michael Foucault, while the subtitle, a little bit less evidently, refers to Zygmunt Krasiński. It is a work of major ambition - to the order of magnitude of giving a Polish Foucault to its readers. Foucault, by the way, is interpreted by the author with great expertise and familiarity with his work. Does the book fulfil this objective? Let's have a look at this issue from the point of view of certain aspects in which this publication contributes to scientific debate. As I was trying to demonstrate up to this point, it is a multi-aspectual tome and any attempts to adequately summarise it or pinpoint the problems tackled within it are bound to fall short, first of all because most of its content consists of case analysis. Therefore, in the present review I shall discuss only these topics that I consider important from the perspective of psychiatric ethics, leaving matters related to historiography or cultural sciences to experts in those fields.

The first and, in my opinion, the most important aspect of the book-also according to the author herself, as can be deduced from what she said during the author's meeting - is the archaeology of terms. She endeavours to reactivate numerous Polish words that were used to describe different mental states in the past and could be used in contemporary psychiatry as well. As the author duly notes, the technical language of science has entered into casual, everyday speech, which forces scientists to use an even more hermetic terminology of ICD codes from the F group (mental disorders) - although these start to seep into the everyday language as well-which, however, were not designed to reflect the versatility of mental states related to sadness, sorrow, longing or regret. Obviously, these processes are significant 
both for common speech, as well as for the language of creativity and that used in the office of a mental health professional who would likely prefer patients not to self-label themselves with technical terms they do not understand, but rather describe their feelings and experiences.

Maybe bringing back the word "smutnodurny"1 to contemporary Polish is not the best idea, but there are also other expressions that the author reintroduces and that in many cases ceased to be used not so long ago: "posępnica," "zaduma," "ponurowatość," or "melancholia" itself - which was still used by Kępiński ${ }^{2}$. The author offers a broad overview of how "melanchology" terms were being forged in Polish, in an effort to come up with equivalents for certain Latin, German, English or French words; providing numerous examples and showing many different semantic hues, as well as the limits of usage. How should we translate the English concept of "spleen" into Polish? Why not refer to the organ with a perfect term such as "śledziennictwo"!

Why is it all significant from the ethical point of view? The author does not write it explicitly, but a major issue in contemporary psychiatric ethics - especially in its popular version-consists in separating mental problems and their symptoms from the social stigma of mental illness, and in avoiding pseudo-psychiatric talk in public space. It turns out that Polish has a huge amount of terms that could be brought back to help in this important task.

Another significant topic concerns the sources of contemporary discussions about medicalisation and the fact that although they are immanent for the area of psychiatric knowledge, there might be some solutions. The author describes 19th-century arguments between somatiker and psychiker, as well as discussions about the thin line between the norm and pathology in such a way that it is obvious for the reader that both parties are wrong and their answers converge in places where meaningful help is provided to those who suffer. She does it by describing cases that not only present the symptoms of those afflicted by melancholy, but their entire personalities together with their assets, specific character features and sometimes different kinds of behaviour. Mira Marcinów shows to the reader that 19th-century psychiatrists knew that intellectual work increases the risk of melancholy and that not every kind of sadness is pathological, although some are. These are questions that in more contemporary times form the axis of dispute between psychiatrists and anti-psychiatrists, or at this moment-even post-psychiatrists. For the sake of such discussions, both theoreticians and clinicians can find it useful to take a step back and look at the similarities between the debates taking place currently and those from 100-200 years ago.

The third essential subject, even if outlined only roughly, is the question of a set of symptoms specific to Polish culture. Researchers exploring the history of psychiatry already know that the same disorders may be experienced by patients differently depending on the cultural context. The delusions of Poles and of the Chinese differ; similarly, mental institutions in former times used to be populated by Napoleons, whereas today a more common affliction consists in thoughts sent by secret state agencies via radio frequency. Mira

\footnotetext{
${ }^{1}$ Literarily ,sad-dumb” in modern Polish.

${ }^{2}$ Famous Polish psychiatry professor and prolific writer of 50's and 60's of $20^{\text {th }}$ century.
} 
Marcinów outlines two symptoms typical for Poles in the times after they had lost sovereignty and were fighting to regain it. Feelings of longing, loss and reminiscence tend to appear repeatedly. On the other hand, the author does not try to diagnose Poles as a community, but rather shows a kind of coherence and continuity with what was observed by psychopathologists in different European countries. It is an important input into the global history of psychiatry and let us hope that these parts of the book will be published in a conference language, because - as the author stresses herself in the introduction - historians of psychiatry give up when it comes to reading texts in Slavic languages.

I suppose that many readers will find it interesting that the book provides a possibility to collate the author's conclusions and analyses with source texts that until now were in their main part unavailable. Many of them were printed a long time ago, with archaic spelling, and can be accessed only in very few libraries. Here, they have been gathered in one tome, which will prove useful not only for historians, but also for practitioners, who will be able to compare their diagnostical and therapeutic skills with those of their colleagues in the past, noticing their advantages, but also certain matters that are easily overlooked in the present, technicalised medicine. One of these motifs consists of descriptions of the melancholic gaze - the main symptom of psychopathology in cases reported by $19^{\text {th }}$-century physicians. Would these descriptions still be valid in contemporary studies based on proper methodology? Time will probably tell.

There are many more such topics in this volume that could capture the interest of psychiatry ethicists or theoreticians, for instance: the development of the concept of a mental disorder as a flaw or a moral problem, the way in which medicalisation stripped the sick of their agency, how supposedly humane and humanistic therapies turn out to be stigmatising. These and many more subjects can be found in this publication.

Now, one may ask: how should we assess this work? I will evaluate the book in different areas and then I will try to issue a general verdict. The easiest to assess is the technical aspect. The book is published in hardcover, on thick, high quality paper. The images are printed on a special paper for photo albums, the typesetting looks good and is stylish, with unique placement of page numbers and headings. Not for lack of trying, I have not been able to find any defects. The book has been edited very scrupulously; well, reportedly, the editorial process took four years. The only element that can raise doubts is the image on the cover. Let's just say it is aesthetically controversial and not take the matter any further, because de gustibus disputandum non est.

Judging from the academic perspective, the book has an extensive list of reference literature, as well as substantial references. All the cited facts are meticulously documented by providing references to literature in a style resembling that of scientific journals. Readerfriendly indexes help to move around the manifold clinical cases. Moreover, the extent of source materials analysed by the author is overwhelming. As she wrote herself in the introduction: they span from $12^{\text {th }}$-century Latin Codes to publications of historians from the second half of the $20^{\text {th }}$ century. Considering that it is the only publication on this topic in 
Poland, it will surely enter the canon of texts used by historians of psychiatry and psychology; time will tell if it will prove interesting for clinicians and influence their practice, or contribute to popularising this field.

The extraordinary erudition of Mira Marcinów is also, definitely, a strong aspect of the book. The author is a philosopher, holds a $\mathrm{PhD}$ in psychology, she is a clinician and is also active, among others, in the area of dance. All of that combined with her knack for the written word results in a text that is interesting to read, without the heaviness typical of thick scientific tomes (the books weighs around 3 kilos). It seems that the author has managed to achieve a rare fusion of a book that can be used as a reference text in a seminar, and a book that can be read for fun on vacation or as a bedside book.

Unfortunately, there are also some negative aspects of this volume that have to be mentioned, and these do influence the final judgement. First of them consists in a certain imbalance of requirements towards the reader. On the one hand, the author explains the absolute basics of contemporary psychiatric nosology, on the other hand, she refers to Kraepelin and psychoanalysts practically without any broader explanation. This might be a very subjective effect of course. Some readers will not even notice this issue, but for others it might render the book completely obscure. In this respect, the book seems to be addressed more to humanists than to medical professionals. On the other hand, however, the source materials are provided without any critical apparatus, in some cases in fragments, which will not make life any easier for historians who will be forced to access original editions anyway. This makes us think that the book is addressed rather to practitioners. This may seem to be a lack of consistency, if not on the part of the author, then on that of the publisher.

The third problem, that has been bothering me since I read this book, is how the album is linked (or not) to the content of the book itself. It is quite significant that the album comes after the table of contents and doesn't have pagination, as if it were attached there by chance. Maybe it would be a better solution if it were somehow integrated with the written narrative? Although the descriptions of images refer to psychopathology, their context is international and they don't fit the topic of Polish madness indicated in the title.

To sum up, the publication has a very rich content, it is a unique publication on the editorial market and the first one on this subject. Each practitioner and theoretician of psychopathology, as well as philosophers and ethicists of psychiatry will find here something interesting for themselves. Nonetheless, there are some things that can still be improved in the second edition.

The editorial and publishing process of this publication has been financed by the Ministry of Science and Higher Education from the funds for the dissemination of research (DUN) within the framework of publishing activity, contract no. 711/P-DUN/2019, period of implementation: the years 2019-2020. 